\title{
0 trabalhador-doente e sua família no contexto do adoecimento, absenteísmo e o processo de retorno ao trabalho
}

\author{
Paulo Roberto Ferreira da Rocha \\ Mônica Angelim Gomes de Lima
}

\section{SciELO Books / SciELO Livros / SciELO Libros}

ROCHA, P.R.F., and LIMA, M.A.G. O trabalhador-doente e sua família no contexto do adoecimento, absenteísmo e o processo de retorno ao trabalho. In: FERNANDES, R.C.P., LIMA, M.A.G., and ARAÚJO, T.M., comps. Tópicos em saúde, ambiente e trabalho: um olhar ampliado [online]. Salvador: EDUFBA, 2014, pp. 451-478. ISBN: 978-65-5630-012-2. https://doi.org/10.7476/9786556300122.0022.

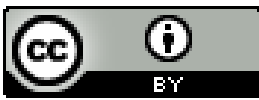

All the contents of this work, except where otherwise noted, is licensed under a Creative Commons Attribution 4.0 International license.

Todo o conteúdo deste trabalho, exceto quando houver ressalva, é publicado sob a licença Creative Commons Atribição $\underline{4.0}$. 


\section{O trabalhador-doente e sua família no contexto do adoecimento, absenteísmo e o processo de retorno ao trabalho}

Paulo Roberto Ferreira da Rocha Mônica Angelim Gomes de Lima

\section{Introdução}

As doenças crônicas, relacionadas ou não ao trabalho, são responsáveis em grande medida pelo absenteísmo e aposentadoria precoce dos trabalhadores. Nos Estados Unidos da América, o total anual de custos diretos e indiretos com o afastamento do trabalhador-doente excede os gastos associados com SIDA e Doença de Alzheimer e alcançam valores equivalentes aos custos totais do câncer e da doença coronariana. No Brasil, os gastos com auxílio doença e tratamento de trabalhadores acidentados chegam a R $\$ 42$ bilhões por ano. (DEMBE, 2002; AGÊNCIA, [2008])

As síndromes que causam incapacidade, muito frequentes nas sociedades contemporâneas, geram grande sofrimento, contribuem para reduzir autonomia do indivíduo e limitar o seu papel social. O significado particular do sujeito, que modela a forma de lidar com a doença pode definir o modo como será atendido pelos serviços de saúde, a relação médico-paciente, a aderência ao tratamento e até mesmo o curso da enfermidade e o tempo de afastamento do trabalho. (KLEINMAN, 1988; FERRARI; KWAN; FRIEL, 2001)

De uma maneira geral entende-se que estar doente, para a maioria das pessoas, é uma condição indesejável, embora seja muito atual no campo da psicologia comportamental a discussão sobre perdas e ganhos para o indivíduo e para o seu entorno. Possivelmente o balanço entre estes influenciará no processo de adoecimento e na permanência no 
estado provocado pela doença. Este debate tem-se orientado no sentido de identificar, nos indivíduos, comportamentos a favor de se manterem doentes sem problematizar as perdas advindas desse processo e sem questionar sobre o contexto no qual esse fenômeno se desenvolve. (FERRARI; KWAN; FRIEL, 2001)

Para entender a contribuição do ambiente social na cronicidade da doença, entre as oscilações dos sintomas e incapacidade, devemos ser capazes de ver o doente envolto em uma rede de relacionamento que constitui o mundo da vida cotidiana ${ }^{1}$. Cabe reconhecer no estudo deste tema as interações que acontecem com os serviços de saúde e os sistemas sociais, que interferem na transição do estado de incapacidade para o estado social normal. (KLEINMAN, 1988)

O trabalhador portador de doença crônica está frequentemente submetido a sérias limitações nas atividades da vida diária em geral e à incapacidade ${ }^{2}$ para o trabalho em particular, além de estar susceptível a aposentadoria precoce. O que se propõe para lidar com a condição de incapacidade é promover a reabilitação do trabalhador-doente o mais breve possível, começando logo que se inicie o tratamento, utilizando processo de gerenciamento que integre os setores clínicos e de saúde ocupacional, os sistemas de seguro e o Estado. (WADDELL; BURTON, 2004)

Para compreensão do que facilita ou dificulta, para o indivíduo, recuperar sua capacidade laboral, deve-se buscar avaliar os fatores biopsicossociais envolvidos. Gatchel e colaboradores (2004) citam como exemplo destes, entre outros, o balanço das perdas e ganhos secundários, os transtornos psíquicos menores, a motivação, a compreensão sobre a doença e os efeitos iatrogênicos do tratamento. Incluem, também, os processos que ocorrem no local de trabalho (política e cultura organizacional), as interações no ambiente da família, as políticas públicas de segurança da saúde do trabalhador, o sistema de crença da comunidade em que vive e dos profissionais da saúde, que se movem ao longo do processo diagnóstico-terapêutico, da experiência humana e

1 O mundo da vida, às vezes chamado de mundo da vida cotidiana refere-se ao mundo experiencial de cada pessoa em atitude natural. (HUSSERL, 1946)

2 A Classificação Internacional de Funcionalidade, Incapacidade e Saúde (CIF), baseada numa abordagem biopsicossocial, define incapacidade como produto da interação entre a disfunção apresentada pelo indivíduo (funções e estruturas do corpo), a limitação das atividades e restrição na participação social, e os fatores ambientais. (WHO, 2001) 
níveis sociais de significados. (ENGEL, 1977; DEMBE, 2003; YOUNG et al., 2005)

A dinâmica desencadeada na interação do trabalhador-doente com sua família, durante a convivência cotidiana pode interferir no tempo de afastamento do trabalho. A doença provoca na família mudanças na sua função e estrutura, exigindo de seus membros um esforço para lidar com as novas demandas provocadas pelo adoecimento. (ROLLAND, 1994) Estudos recentes de Dembe (2002), Franche e Krause (2002), Baril, Berthelette e Massicotte (2003), Allebeck e Mastekaasa (2004) e Rocha (2010) apontam a importância de reconhecer as situações geradas na família, em consequência do afastamento do trabalhador para se obter elementos que possam ajudar a compreender e gerenciar a reabilitação profissional.

Para ampliar o entendimento sobre as dinâmicas que ocorrem no ambiente da família, no processo de afastamento do trabalhador/doente, apresenta-se neste capítulo, uma revisão narrativa desta temática reunindo informações sobre as repercussões biopsicossociais do adoecimento do trabalhador, as dinâmicas familiares na relação com o trabalhador doente afastado do trabalho e o processo de retorno ao trabalho de afastamentos prolongados.

\section{Método}

Trata-se de uma revisão narrativa da literatura no período de 1991 a 2010, em bases de dados indexadas (Lilacs, Medline, Google Acadêmico) e livros especializados, em língua inglesa e portuguesa. Este método de pesquisa permite apresentar informações atualizadas de maneira exploratória, contribuindo para o delineamento da problemática e de futuras questões de pesquisa. (SLAVIN, 1995) A abrangência temporal possibilitou identificar a evolução desta discussão, no que diz respeito às mudanças da conformação das famílias e do entendimento sobre incapacidade para o trabalho. Nesta revisão foram incluídos estudos controlados, revisões sistemáticas, estudos de coortes e caso-controle, além de capítulos de livros. Foram excluídos os textos não disponibilizados e os que não tratavam dos tópicos de interesse da pesquisa. A limitação deste método se define pela forma subjetiva de escolha, da análise e conclusões dos estudos selecionados. (GELIJNS, 1990) 
Nesta perspectiva, buscou-se apresentar a atual discussão sobre a interação entre trabalhador-doente e sua família e as repercussões sobre a situação de incapacidade e do retorno ao trabalho. As palavras-chave utilizadas na busca foram em português: doença crônica-incapacidade, incapacidade-absenteísmo, a família no contexto do adoecimento do trabalhador, apoio à reabilitação-família, reabilitação e o processo de retorno ao trabalho ( em Inglês: "family and process of returning to work", "chronic disease and absenteeism", "family and illness of worker" e "family and rehabilitation"). Procurou-se examinar a literatura quanto às mudanças na estrutura e função da família, em consequência da presença do trabalhador-doente na residência; mudanças no seu papel social e as interações que acontecem com o serviço de saúde durante o processo de adoecimento e reabilitação. Estes aspectos permitem uma melhor compreensão sobre o tema e o reconhecimento da importância das diferentes dinâmicas familiares como facilitador ou obstáculo para o retorno ao trabalho do trabalhador-doente.

Com o objetivo de apresentar os achados da literatura e tornar compreensível a multidimensionalidade envolvida no processo de adoecimento e recuperação do trabalhador e sua família, dividimos este capítulo em três secções que abordam: 1- As facetas do adoecimento do trabalhador: as repercussões biopsicossociais; 2- As dinâmicas da família na relação com o trabalhador-doente afastado do trabalho; e 3- O processo de retorno ao trabalho: sua complexidade, os papéis dos atores sociais e a importância da família na recuperação do trabalhador.

\section{Resultados e discussão}

\section{As facetas do adoecimento do trabalhador: as repercussões biopsicossociais}

Segundo Kelly (2001), a trajetória do adoecimento se apresenta sob quatro facetas assim descritas: a fisiológica, que versa sobre as interpretações do paciente em relação aos aspectos biológicos e os processos inerentes à própria doença; a temporal, refletindo os significados vindos do uso do tempo (horários de consultas, fisioterapia, etc.); o sentimental, reconhecido pelas interações envolvendo em profundidade 
os anseios e emoções diante da possibilidade de confrontar dor ou morte; e a social, que se apresenta como resultado das interpretações que os indivíduos dão às atividades cotidianas que compõem os cuidados à saúde em sua totalidade.

O trabalhador-doente quase sempre tem restrições fisiológicas para executar as atividades diárias em casa e no trabalho como consequência primária da dor, fadiga e limitações físicas. Durante o adoecimento de um dos seus membros, a depender da forma como a família está estruturada, este fato pode levar à tensão e, até mesmo, à desestruturação. A magnitude do problema e a habilidade para lidar com a incapacidade estão na dependência do perfil do sujeito (capacidade de percepção, sexo, escolaridade e idade) e do suporte social presente, com grande variação do grau de repercussão biopsicossocial. (BOOT et al., 2008)

Durante a trajetória de adoecimento o trabalhador pode experimentar uma serie de eventos de natureza sentimental. A perda da atividade produtiva, a crise financeira, o estresse na família, o estigma e a dependência física e emocional conduzem o trabalhador-doente a perder a autoestima e a identidade pessoal, levando a uma diminuição do controle sobre a própria vida e o futuro. O sofrimento se expressa não só pela dor física, estresse psicológico ou pelos efeitos deletérios do tratamento, mas também pelo amplo significado dado à convivência com os membros da família e as repercussões do adoecimento nestas relações. As experiências do passado sobre as quais foi construída uma imagem positiva, agora não estão mais disponíveis. O modo de apresentação do problema está na dependência do modo de ver, dos valores adquiridos e na forma de viver no mundo. (CHARMAZ, 1983)

A doença remete a outra dimensão referente ao papel social que o sujeito doente assume na sociedade e tem variado a sua legitimação ao longo do tempo e cultura. Envolve os direitos e as obrigações que o sujeito tem de cumprir como parte da interação social. (PARSONS, 1964) A flexibilização das exigências na representação do papel social, é muitas vezes legitimada por um médico através de um diagnóstico e emissão de atestado, notificando a incapacidade do trabalhador e determinando o tempo de afastamento do trabalho.

No ambiente da empresa, as condições que contribuem para o adoecimento e o afastamento prolongado do trabalho estão relacionadas, em grande medida, à organização do trabalho como: o tempo 
de execução das tarefas prescritas (ritmo e tempo de jornada, hora de descanso), concepção do trabalho (complexidade da tarefa, habilidade e esforço pessoal, controle do trabalho), relacionamento interpessoal (relação com supervisores e colegas), perspectiva de crescimento, possibilidade de demissão, estilo de gerenciamento e característica organizacional (ambientação, cultura). Além desses, citam-se a falta de apoio social no trabalho, como disponibilização de seguro de saúde patrocinado pelo empregador e a inexistência de programas de prevenção de doenças e ergonomia no trabalho. (NIOSH, 1996; DEMBE, 2002; WADDELL; BURTON, 2006)

Outras condições relacionadas ao trabalhador e ao ambiente de trabalho têm sido descritas como responsáveis pelo absenteísmo nas empresas. Vingard e colaboradores (2005) acompanharam 5.224 mulheres empregadas do setor público durante três anos, incluindo as trabalhadoras que responderam que estavam bem de saúde. Ao final do seguimento observou-se que 918 delas estiveram afastadas do trabalho por mais de 28 dias. As análises uni-variadas e multivariadas, destinadas a avaliar os fatores associados ao absenteísmo, evidenciaram associação estatisticamente significante com idade (risco Relativo $(R R=1,4)$, obesidade $(R R=1,3)$, assédio moral $(R R=1,5)$, demanda física maior do que a capacidade de trabalho $(R R=1,5)$ e demanda psíquica maior do que a capacidade $(R R=1,2))$. Os autores concluíram que esses fatores, considerados como evitáveis, poderiam ser prevenidos e gerenciados no ambiente das empresas.

O processo de adoecimento também conduz a uma identidade de trabalhador-doente no espaço da empresa implicando, muitas vezes, em submissão ao discurso médico. Sair dessa condição independe da vontade individual. Esta nova identidade é reforçada por um conjunto de práticas linguísticas ou de mediadores sócio funcionais que, nem sempre, são aceitas sem resistência pelos atores sociais que fazem o movimento duplo de subordinação e insubordinação para driblar as formas de exclusão do trabalho. Embora a aceitação da situação vivenciada implique garantia do trabalho, não é o suficiente para evitar o estigma de portador de uma doença. (BRANT; MINAYO, 2004)

Por outro lado, podemos dizer que o fato de um trabalhador estar doente não significa estar de licença médica. Muitas vezes, o trabalhador continua na atividade laboral, mesmo com dificuldade para 
o desempenho das tarefas com o objetivo de manter-se empregado; sabe que se estiver desempregado experimentará dificuldades ainda maiores para se reinserir no mercado de trabalho. (ALEXANDERSON; NORLUND, 2004)

Estudos de Boden e colaboradores (2001) e Burton e colaboradores (2002), mostram que o trabalhador-doente tem maior chance de se ausentar do trabalho e, em longo prazo, pode apresentar mudanças na qualidade e expectativa de vida. Evidências neste sentido estão descritas no estudo de coorte prospectivo de Vahtere, Pentti e Kivima (2004), realizado na Finlândia com trabalhadores do setor público municipal, para determinar se o absenteísmo por motivo de doença é um fator preditivo de mortalidade. Foram incluídos na pesquisa 41.736 trabalhadores sendo $69,3 \%$ do sexo feminino com média de idade de 45,9 anos. Após tempo médio de acompanhamento de 4,5 anos os autores encontraram os seguintes resultados (ajustando-se os dados por idade, estado ocupacional e tipo de contrato de trabalho): mortalidade de 4,3 vezes maior para homens (IC de 95\%: 2,6-7,0) e 3,3 vezes maior para mulheres (IC de 95\%: 2,1-5,3) no grupo de trabalhadores que apresentou um ou mais períodos de absenteísmo prolongado (considerado $>3$ dias), em comparação com os trabalhadores que não se ausentaram do trabalho. Os autores concluíram que as evidências mostram maior mortalidade nesta população por todas as causas, inclusive as relacionadas à doença cardiovascular, câncer, complicação do alcoolismo e suicídio.

Burton e colaboradores (2002) no estudo sobre as consequências psicossociais do adoecimento relatam que: o trabalhador arca com $30 \%$ do total das despesas resultante do absenteísmo; a personalidade do indivíduo influencia o modo como ele ou ela reage ao adoecimento; às vezes, por ser um processo de diagnóstico e evolução lentos, este dificulta o reconhecimento do sujeito de que estava doente; a doença pode causar estresse emocional e isolamento social, interferindo no convívio com os familiares; os pesquisados relataram falta de suporte por parte das instituições responsáveis pelo seu atendimento e oito dos quinze casos entrevistados referiram que sua profissão foi afetada diretamente pela doença. Todos estes fatores foram citados como responsáveis pela reduzida capacidade de lidar com a condição de incapacitado, assim como de dificultar a recuperação profissional. 
Bernardo (2006) chama atenção sobre a experiência do afastamento do trabalho por doença, que apesar do reconhecimento e consciência de se tratar de uma situação, na maioria das vezes, provisória, provoca nos trabalhadores uma "ilusão de trabalho", principalmente quando o afastamento é de longa duração, porque continuam a receber parte do salário. Entretanto, a possibilidade de perder a renda e de ter que sobreviver exclusivamente do benefício pago pela previdência social, que geralmente é inferior ao que usualmente se ganhava, é uma constante em suas vidas. $\mathrm{O}$ trabalhador do setor privado sofre com a possibilidade de desemprego, pois a sua recuperação ou reabilitação não garante o retorno ao trabalho. Em alguns casos o futuro não parece promissor, pois há o risco concreto do preconceito, do estigma e da incompreensão das empresas para sua reinserção no trabalho. No setor público, apesar da estabilidade do servidor no emprego, durante o adoecimento também se observa perdas de vantagens salariais que interfere no processo de recuperação e a perspectiva de alcançar crescimento profissional fica ameaçada pelo afastamento do trabalho.

As demandas atuais impostas pelas organizações têm desafiado o trabalhador em combinar as tarefas do trabalho e as necessidades da vida familiar. Em consequência da sobrecarga do turno estendido, assim como do número crescente de famílias monoparentais e de casais que trabalham fora de casa, associado à dupla jornada de trabalho, a falta de energia do trabalhador para lidar com assuntos do cotidiano doméstico é uma temática recorrente. O conflito de interesse entre empresa e família é reconhecido como um fator de absenteísmo principalmente no sexo feminino. (JANSEN et al., 2006)

Outro aspecto também a ser considerado durante o processo de adoecimento refere-se à economia das perdas e ganhos. O papel dos ganhos secundários, seja motivado de causa psicológica, ou de outras formas, como os tipicamente associados a ganhos monetários, evitar obrigações sociais, dentre outros, tem sido considerado como uma importante barreira para a recuperação do trabalhador incapacitado por motivo de doença. Embora seja um tema extremamente controverso e fonte de discussão na área médico-legal e social, entende-se como necessário seu reconhecimento nos processos de retorno ao trabalho, como parte das demandas para o gerenciamento de programas de reabilitação. 
Entretanto, segundo Gatchel e colaboradores (2004), esse conceito está vinculado erroneamente ao fingimento consciente do paciente para receber benefícios financeiros. Este autor chama atenção aos prejuízos que este ponto de vista traz ao paciente: gera a ampliação de seu esforço para obter a legitimação do adoecimento, acentua seu sentimento de injustiça, leva-o a resistir ao reconhecimento de resultados terapêuticos e influencia no prolongamento do afastamento do trabalho. Aponta ainda a necessidade de identificar e incluir também, neste registro, as perdas secundárias que se infiltram praticamente em todos os domínios da vida do indivíduo doente e incapacitado. A perda da autonomia, as mudanças das relações sociais, a instabilidade financeira, a dificuldade de manutenção do emprego, as mudanças dos papéis familiares, o impacto sobre a autoestima, e mesmo sobre a visão geral do mundo, influenciam o comportamento do indivíduo em relação à doença e à incapacidade prolongada.

Neste contexto devem-se analisar também as perdas e ganhos terciários, que são aqueles obtidos ou perdidos com a doença por alguém, que não o próprio paciente, um membro da família, um médico, etc. O resultado desta economia de perdas e ganhos pode influenciar o tempo de afastamento do trabalho e, por razões óbvias, por exemplo, quando as perdas superam os ganhos, servem de reforço para um retorno ao trabalho precoce, sem a adequada reabilitação. (KWAN; FRIEL, 2002; DERSH et al., 2004)

Segundo Kaiser (1998), as explicações que determinam o comportamento de absenteísmo, sob uma perspectiva interdisciplinar (psicologia organizacional, psicologia social e economia) devem ir além dos significados isolados dos modelos de motivação individual, social e econômico, entendidos aqui como não mutuamente exclusivos e sim interdependentes e complementares. No modelo explicativo, que incorpora a motivação individual, se distinguem três categorias: a característica pessoal (valores pessoais, personalidade, atitude frente ao trabalho, aspecto demográfico e status social); a resposta individual ao estímulo no ambiente organizacional (por exemplo, tipo e condição de trabalho); e as respostas aos estímulos, aos ambientes fora do trabalho (circunstâncias da vida e da família, valores do uso do tempo fora do trabalho). O modelo psicossocial reconhece que a decisão de estar ausente será tomada em diferentes circunstâncias baseada no pressuposto que 
o trabalhador assume, observando tanto o status e o comportamento dos outros trabalhadores (dentro e fora da organização), como os sentimentos de igualdade e de justiça. O modelo econômico sugere que em grande medida, os benefícios e custos associados com o absenteísmo são ditados pelas forças do mercado de trabalho. Enfim, esses três modelos presentes em uma abordagem biopsicossocial, conduz a um melhor entendimento da(s) causa(s) do afastamento do trabalhador e vai de encontro ao peso relativo de cada modelo nas circunstâncias em que a ausência ao trabalho for observada.

O trabalhador-doente, incapacitado e afastado do trabalho, independentemente do motivo que o levou à situação de restrição das atividades e necessidade de suporte, procura abrigo no ambiente da família onde se sente acolhido. É neste local, considerado como um sistema de saúde, que procura cicatrizar as suas "feridas" provocadas por uma doença que não esperava e que lhe roubou a vitalidade e a perspectiva de viver com um futuro promissor.

O sujeito procura aportar em um lugar seguro onde os pares lhe são familiares e que já ganhou a confiança após anos de convivência. É exatamente no seu mundo familiar que tem de representar o seu novo papel, o de doente e que nem sempre será bem interpretado ou compreendido. A família, no seu processo de transformação, absorverá ou não este impacto na dependência da forma como os seus membros agem e gerenciam esta nova contingência.

\section{As dinâmicas da família na relação com o trabalhador-doente afastado do trabalho}

Singly (2007), em publicação sobre a Sociologia da Família Contemporânea chama atenção sobre as transformações ocorridas nas últimas décadas na família, em termos de estrutura e função, em consequência do modo como os seus membros se posicionam no cotidiano contemporâneo, resultado das mudanças derivadas das relações de gênero, da inserção intensiva da mulher no mercado de trabalho e da maior mobilidade conjugal. A família participa do dinamismo intrínseco às relações sociais e sofre influências do contexto político, econômico e cultural. Torna-se cada vez mais relacional, ainda que inscrita num processo de individualização e autonomização de seus membros. Processo que não 
se restringe aos papéis ordenados pela instituição família, mas uma forma contemporânea de criar laços sociais.

As transformações na sociedade fizeram com que a família mudasse de forma e sentido. Em lugar de se impor aos seus membros, a família se tornou, de alguma maneira, um "serviço" que pode ser colocado à disposição dos indivíduos preocupados em viver juntos. Na atualidade, a definição de família fica mais complicada até para os seus próprios atores sociais, diante da dificuldade para delimitar os seus contornos mutantes. (SINGLY, 2007)

Podemos dizer que a família é relacional porque existe ligação através dos pais e filhos, e ela está inserida em um cotidiano complexo onde seus membros, mesmo mantendo sua individualidade, compartilham sentimentos e valores formando vínculos de interesse, solidariedade e reciprocidade. A família é também, ao mesmo tempo, pública e privada, pois se caracteriza pela sua relativa dependência em relação ao Estado e aos grupos de parentesco. Os homens e as mulheres, os adultos e as crianças organizam suas vidas privadas no quadro da dualidade: buscam sua independência em termos individuais e mantém uma dependência da esfera pública. Ainda em relação a este ponto de vista, observam-se mudanças na função da família onde os seus papéis foram transferidos para outras instituições (escolas, creches) fruto da inserção da mulher no mercado de trabalho e da globalização da sociedade. (SIMIONATO; OLIVEIRA, 2003; SINGLY, 2007)

$\mathrm{Na}$ perspectiva do modelo sistêmico, a família desempenha suas funções incorporando os conceitos de organização referente à sua força, papéis, hierarquia e integridade de fronteiras; adaptabilidade (flexibilidade versus rigidez), coesão (estar juntos ou afastados) e estilo de comunicação. Dessa forma, executa três tipos de tarefas no cuidado dos seus membros na convivência cotidiana: o básico, como obter alimento e abrigo; o apoio ao desenvolvimento em busca de novos horizontes sociais e o de proteção frente às situações adversas como uma doença e incapacidade. Contudo, existem inúmeras situações contemporâneas que fogem aos padrões descritos acima e que determinam outras formas da família agir e gerenciar o cuidado dos seus membros. (BERTALANFFY, 1969; ROLLAND, 1994)

O papel social da família inclui, entre outros, o cuidado da saúde que transita entre o autoevidente e o velado, a administração das 
economias e o suporte para facilitar a condição de trabalho de seus membros. A família tem uma materialidade onde, na convivência entre seus membros, ora como pano de fundo, ora como determinante explícito é tecida a especificidade de cada sujeito. Quando acometido por uma doença, os membros apoiam-se mutuamente, buscam e mediam esforços para atenuar ou resolver o impacto do adoecimento e desempenham seus papéis, que são as expectativas de comportamento, obrigações e direitos respeitando a sua posição no grupo familiar influenciado pelas circunstâncias sociais e culturais. (ROLLAND, 1994)

Quando uma doença atinge um indivíduo, se expressa em certo contexto, que é resultado de uma construção social, como um processo que não é simples e que envolve múltiplos sistemas de significado, interagindo nesse momento especial de vida. Dessa forma, o processo de adoecimento está envolto a uma complexa rede de significados produzidos pelos atores sociais envolvidos, numa constante edificação e redefinição. Na maioria das vezes o trabalhador-doente se encontra no "olho deste furacão" de significados correntes e pode muito bem ser imobilizado, dificultando a sua recuperação. (BLOCH, 1994)

As consequências não se restringem apenas aos efeitos no doente, mas dependendo da fase de desenvolvimento da família pode abranger todos os seus membros, requerendo deles um esforço desafiador para organizar a estrutura familiar ao longo dos diversos ciclos da vida. Por sua parte, a família tem uma estrutura organizacional própria para enfrentar as situações rotineiras e de contingências e, desta forma, tenta administrar habilmente suas demandas através da construção de certos padrões representados pela divisão de responsabilidades, hierarquia e delimitação de fronteiras entre os seus membros. (SACHS; ELLENBERG, 1994)

Dembe (2002), em um artigo de revisão sobre o adoecimento do trabalhador e suas consequências sociais, mostra evidências de que o adoecimento do trabalhador está associado à alteração do seu bem-estar, mudanças no convívio no interior da família e desestruturação da sua condição financeira. Diz ainda que as consequências sociais, difíceis de serem mensuradas na prática, envolvem as diversas relações recíprocas entre os diversos atores participantes deste processo. Estão também na dependência da magnitude da incapacidade provocada pela doença, do 
perfil sociodemográfico, da experiência com os serviços de saúde e com a seguridade social e dos efeitos, em particular, no ambiente da família.

O trabalhador-doente se vê diante de mudanças nos seus hábitos e em seu estilo de vida. Percebe-se diante de inúmeras perdas de seus papéis e de suas responsabilidades e o retorno à convivência dentro do ambiente familiar obriga-o a renegociar a sua identidade. Ele se sente como se fosse outra pessoa e descreve que as mudanças que acontecem na sua vida se estendem além das limitações físicas provocadas pela enfermidade. Como resultado dessa reestruturação, experimenta sentimento de culpa, ansiedade e depressão que podem interferir na forma de conviver na família. (STRUNIN; BODEN, 2004)

A redescoberta do domicílio familiar acontece quando se vê obrigado a ficar em casa diuturnamente por causa da doença. Como é o único lugar onde passa a viver, requer que desenvolva pluralidade e criatividade para sobreviver. A arte de estar entre os membros de sua família, na atual circunstância determina a construção de uma nova ação do que se espera das regras de convivência e manutenção dos vínculos parentais. (CERTEAU, 1988)

Sabe-se que algumas famílias estão mais bem preparadas do que outras para gerenciar as mudanças provocadas pela doença. São capazes de tolerar situações de alto estresse através da troca dos papéis (alguém assume o papel para fazer certas atividades domésticas em substituição ao doente) e, desta forma, tentam enfrentar os problemas de maneira mais eficiente. Entretanto, o grau de incapacidade do trabalhador-doente vai determinar um estresse adicional à família.

A forma de administrar esta nova demanda implica negociação das fronteiras individuais, que esbarra na importância dos papéis desempenhados por cada membro. Na divisão das tarefas domésticas há um espaço para o surgimento de novos conflitos ou acentuação de antigos mal resolvidos. (ROLLAND, 1994) Muitas vezes, o ambiente familiar está desestruturado pelas circunstâncias sociais contemporâneas, resultado das mudanças profundas e permanentes que dizem respeito à atividade produtiva e a organização do trabalho, devido às condições geradas pelas relações atuais de emprego, produzidas pelas situações de baixa remuneração, fragilidade dos vínculos empregatícios e turnos extensos de trabalho. (GOMES, 2008) Diante de tal perspectiva, o mundo da vida cotidiana ganha uma dimensão mais complexa, exigindo 
de cada membro um esforço particular para manter o equilíbrio nas relações interpessoais.

Por outro lado, alguns assumem que o trabalhador doente, se recuperando em casa, vai ter mais tempo para os afazeres domésticos. Em certas circunstâncias isto é possível, particularmente se as atividades realizadas não demandam muito esforço. Entretanto, a incapacidade provocada pela doença na execução do trabalho na empresa se estende também às tarefas executadas no cotidiano da residência, interferindo com a autoestima e autoconfiança do indivíduo, chegando ao ponto de criar obstáculo na interação habitual da família. (BODEN et al., 2001)

O afastamento do trabalho e o impacto do adoecimento nas famílias que tem uma única fonte de renda, geralmente originada do trabalho assalariado, serão de grande monta, principalmente se houver redução salarial por conta de perdas dos complementos recebidos durante o turno de trabalho. Algumas vezes, a cobertura do seguro social é insuficiente para absorver as crescentes demandas de gastos com medicamentos, consultas a especialistas, deslocamento para os serviços de tratamento e recuperação. (BODEN, 2005)

A revisão de literatura de Foreman, Murphy e Swerissen, (2006) mostra os principais fatores que facilitam ou dificultam o retorno ao trabalho, entre estes a oferta de serviços especializados para o tratamento, o papel da seguridade social ou outras dimensões de apoio no ambiente da empresa. Contudo, pouco ou raramente se encontram estudos avaliando o impacto econômico no cotidiano familiar dos trabalhadores afastados por doença, merecendo maior atenção dos pesquisadores interessados nesta problemática. (DEMBE, 2002)

O tempo que o trabalhador-doente passa em casa é determinado não só pelo grau de incapacidade em consequência da doença, mas também pelas circunstâncias do seu convívio no ambiente familiar. Esse processo pode ser longo e de alto custo para o indivíduo isoladamente ou para a sociedade como um todo. Rocha (2010), em estudo realizado com servidores públicos da Universidade Federal da Bahia afastados do trabalho, por motivo de doença, observou que o apoio dos familiares atuava como um fator importante na recuperação da incapacidade e era considerado como um facilitador positivo para o retorno ao trabalho. A contribuição mais significativa desta pesquisa foi desvelar a importância do papel da família na reabilitação do trabalhador-doente atra- 
vés do relato das experiências sobre as dificuldades dos servidores na convivência cotidiana em casa.

A recuperação do trabalhador com incapacidade é um dos maiores desafios para os serviços de saúde porque têm de lidar com os aspectos físicos, psíquicos e sociais da doença e com fatores contextuais. Para melhor gerenciar o processo de retorno ao trabalho, autores como Schultz e Stewart (2008) e Loisel et al. (1994) propõem um modelo de abordagem biopsicossocial que integre as suas ações, intervindo nas barreiras e nos facilitadores contextuais (sistema de saúde, previdência social, local de trabalho e contexto pessoal, onde está presente a família). Trata-se de um modelo de atuação voltado à prevenção da incapacidade prolongada, que incorpora o sistema de crença, os profissionais da saúde, pacientes e família de maneira flexível, para além do tratamento biomédico. (LOISEL 2007)

Neste horizonte de significados distintos e muitas vezes tensionados, em um momento de profundas mudanças provocadas pelo adoecimento, as demandas dos processos de trabalho e familiares surge a necessidade de gerenciamento deste processo por parte dos diversos atores sociais envolvidos com a reabilitação de pessoas. Um suporte importante tem sido os posicionamentos assumidos pela Organização Internacional do Trabalho (OIT, Convenção nº159 e Recomendação $\left.\mathrm{n}^{\circ} 168\right)$. Desta forma, empresa, sistemas de saúde e o Estado devem se mobilizar para recuperar e reinserir o trabalhador o mais brevemente possível ao mercado de trabalho.

\section{O processo de retorno ao trabalho}

O processo de retorno ao trabalho do trabalhador-doente é complexo, envolve, como mencionado anteriormente, os aspectos relacionados à doença e ao doente, ao tratamento, aos fatores do local de trabalho (organização, função, cultura) e aos fatores fora do ambiente do trabalho como atitude da família e as políticas públicas de saúde do trabalhador. Inclui muitos atores sociais com distintos papéis, objetivos e prioridades. Essas diferentes perspectivas refletem significados que os indivíduos, dos diferentes sistemas, atribuem às mudanças provocadas pela doença, a natureza da interação com o trabalhador-doente e a da relação com o trabalho. (BARIL; BERTHELETTE; MASSICOTTE, 2003) 
Engloba também uma série de eventos desde a fase inicial do diagnóstico da condição clínica, que motivou o afastamento do trabalhador e provocou a incapacidade, até o resultado satisfatório (recuperação laboral) a curto, médio ou a longo prazo. Diferentes ocorrências têm características particulares e consequências distintas a depender das etapas do seu acompanhamento.

Para melhor gerenciamento deste processo Franche e Krause (2002) sugerem três fases evolutivas, definidas pelo número de dias de afastamento do trabalho: aguda ( $\leq 1$ mês); subaguda (2-3 meses) e crônica (>3 meses). Young e colaboradores (2005) propõem um modelo conceitual baseado na dinâmica na qual a condição de incapacidade é desenvolvida em etapas: fase 1 ou de afastamento do trabalho, período durante o qual há recuperação de parte da capacidade funcional; fase 2 ou de reentrada ao trabalho, período que o trabalhador recomeça o seu trabalho; fase 3 ou de manutenção, durante a qual o trabalhador se esforça para manter a sua recuperação e fase 4 ou de avanço, quando o trabalhador experimenta novas qualificações.

De uma forma geral, as ações desenvolvidas para gerenciar a recuperação do trabalhador são realizadas pelos serviços de saúde ocupacional; nos quais, na maioria das vezes, são empregados apenas os princípios médicos de tratamento - um tipo de acompanhamento considerado como linear e que tem por objetivo fazer o diagnóstico e estimar o período necessário de afastamento laboral. A trajetória que o trabalhador doente segue para se recuperar é construída durante as consultas médica e/ou cirúrgica e no acompanhamento no setor de reabilitação profissional (fisioterapia, de terapia ocupacional, serviço social). O quê se vê, na maioria dos casos, é um total desconhecimento do trabalhador dos caminhos necessários para a sua recuperação e reintegração ao trabalho (BERNARDO, 2006).

Nesta perspectiva, a condição para o retorno ao trabalho limita-se à resolução da situação clínica baseada no seu estadiamento e extensão da incapacidade. Dessa forma, perde-se a oportunidade de compreender a complexidade e as várias dimensões deste processo, principalmente as que fazem parte de outras áreas de interdependência deste sistema. (BARIL; BERTHELETTE, D.; MASSICOTTE; 2003)

Partindo deste pressuposto, Takahashi (2000) comparou dois modelos assistenciais para portadores de Lesões por Esforço Repetitivo 
(LER) em serviços de Reabilitação Profissional do Instituto Nacional de Seguro Social do Brasil (INSS) ${ }^{3}$. O primeiro modelo (biopsicossocial), implantado no Centro de Reabilitação Profissional de Campinas/ São Paulo apresentava uma proposta inovadora de atendimento onde se realizava ações terapêuticas integrais por uma equipe multidisciplinar. O segundo modelo (biomédico), no Núcleo de Reabilitação Profissional de Americana/São Paulo considerado como tradicional, de atenção mínima, restrito praticamente a abordagem pericial e com objetivos exclusivos de reinserção imediata do trabalhador-doente ao trabalho. Utilizando uma metodologia avaliativa que comparou os resultados de intervenção no resgate da autonomia de adoecidos com LER, a autora concluiu que o primeiro modelo se mostrou mais adequado para a reabilitação desses trabalhadores. Este achado está em consonância com as pesquisas mais recentes que reforçam a ideia de que o modelo biopsicossocial parece ser o mais adequado para acompanhar o trabalhador incapacitado por doença. (SCHULTZ; STEWART, 2008)

Posto que o retorno ao trabalho do trabalhador-doente é multifatorial, entende-se de uma maneira geral que é difícil fazer uma previsão, com precisão, de quando o retorno acontecerá, usando apenas como referência o conhecimento médico e as características da doença. Depende, sobretudo das ações gerenciais empregadas para lidar com as interações dos fatores biológico, psíquico e ambiental. A depender da condição que levou ao afastamento observa-se uma predominância de um fator sobre o outro. A Figura 1 é possível descrever a complexidade da rede de interdependência que envolve os principais fatores biopsicossociais.

3 Serviços executores de reabilitação do INSS representados pelos Núcleos e Centros de Reabilitação profissional que se encontram atualmente com função apenas reguladora, sendo destituída de qualquer atividade terapêutica. 
Figura 1 - Rede de interdependência dos fatores biopsicossociais

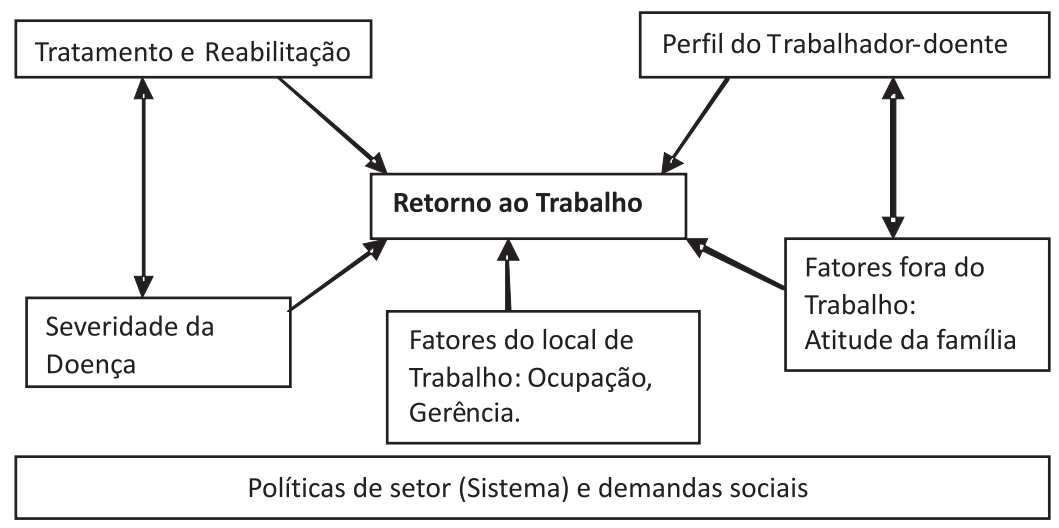

Fonte: (FOREMAN; MURPHY; SWERI, 2006).

Como o processo de retorno ao trabalho pode ser longo e custoso deve-se buscar as informações e analisar se as condições biopsicossociais que levaram ao afastamento do trabalho foram estabilizadas, a fim de determinar se o indivíduo recuperou sua capacidade laboral e se as condições do contexto de trabalho permitem este retorno. É importante ressaltar que o gerenciamento do retorno ao trabalho implica reconhecer que a condição de afastamento prolongado implica aumento do custo com os cuidados com a saúde; baixa (35\%) reinserção do trabalhador incapacitado no mercado de trabalho em comparação com a população adulta normal (78\%) e o desconhecimento sobre os efeitos em longo prazo da incapacidade do trabalhador-doente. (YOUNG et al., 2005)

No início do afastamento, o indivíduo não tem a noção exata da extensão da sua incapacidade e à proporção que o tempo passa e a recuperação funcional demora é que se percebe que a situação é mais complexa. O trabalhador apresenta mudança no estilo de vida que é dependente da natureza da doença, do grau e persistência da incapacidade, das suas necessidades econômicas e das preferências de lazer e consumo que adota. Por exemplo, uma pessoa doente que tem boas condições financeiras pode se afastar do trabalho e esperar a recuperação, enquanto outras são impedidas de realizar o afastamento por causa da limitação econômica, da obrigação de suprir as necessidades básicas familiares - o que força o trabalhador a fazer adaptações ou a procurar outras formas de trabalho. Além da perda salarial, tem-se que lidar com 
a depreciação dos hábitos e habilidade do trabalho, o que leva ao declínio de produtividade e de rendimentos futuros. Por outro lado, maior tempo de incapacidade é um importante determinante da probabilidade de estar empregado após um ano de afastamento; quanto mais retardada for a reinserção, maior repercussão terá na vida do trabalhador. (BOUND et al., 2003; GALIZZI; BODEN, 2003)

As observações aqui apresentadas reforçam o conceito de que quanto mais precocemente forem adotadas as medidas apropriadas para a reabilitação do trabalhador-doente, mais rápido será o seu retorno ao trabalho. Além disso, um grande número de estudos aponta para a relação entre doença e aposentadoria precoce, o que pode ser indesejável para alguns e representar para o sujeito uma perda do poder aquisitivo e isolamento social. Bound e colaboradores (2003), com base em dados dos US Health and Retirement Study, estimaram que trabalhadores com problema de saúde tem dez vezes mais chance para se aposentar em comparação com indivíduos saudáveis. Dados obtidos do serviço público no Brasil mostram uma elevada percentagem de servidores sendo aposentados precocemente por falta de melhor gerenciamento da doença do trabalhador. (DOMINGUES JÚNIOR, 2005)

Algumas condições, de uma forma geral estão associadas com o tempo de afastamento prolongado do trabalho. Além das inerentes à própria doença, vale a pena ressaltar as que dizem respeito ao trabalhador, como a idade (indivíduos de maior faixa etária), o sexo (o feminino) e a baixa escolaridade. Em relação aos fatores psicossociais, a literatura aponta como causa de absenteísmo prolongado a organização do trabalho, com ênfase no efeito do baixo controle e alta demanda nas situações de trabalho. Além disso, citam-se a falta de informação do trabalhador sobre o modo como deve ser acompanhado pelo serviço de saúde ocupacional, o desconhecimento sobre os seus direitos e o baixo comprometimento dos colegas e supervisores. (DEMBE, 2002; LABRIOLA, 2006)

Franche e colaboradores (2002) sugerem que para se alcançar melhores resultados no processo de reabilitação é imprescindível ter uma relação partilhada entre as partes interessadas. Devem-se incorporar atores sociais como a família, os representantes da empresa (supervisores e diretores), os profissionais da área da saúde (médico, fisioterapeuta, terapeuta ocupacional e assistente social) e os representantes 
da seguridade social. O sucesso dos programas de retorno ao trabalho é proporcional à interação entre empregador, trabalhador e demais atores sociais interessados. No contexto brasileiro, a assimetria de poder dessas relações tem sido objeto de questionamento entre pesquisadores da área de saúde do trabalhador. (MAENO; TAKAHASHI; LIMA, 2009)

Segundo Loisel (2007), os atores sociais envolvidos no processo de retorno ao trabalho devem observar os múltiplos significados atribuídos pelo trabalhador-doente ao adoecimento e à sua relação com o trabalho, na dimensão cultural e cognitiva, assim como reconhecer as situações geradas pelo afastamento do trabalho, para melhor compreender a incapacidade e obter elementos que ajudem a gerenciar a reabilitação profissional. Posto desta forma evita-se colocar o trabalhador como um "simples objeto perdido" neste sistema, resgatando seu lugar de sujeito do cuidado.

Franche e colaboradores (2005), em revisão sistemática da literatura, sugerem as melhores intervenções para se reduzir a duração da incapacidade para o trabalho. Em relação aos achados de estudos quantitativos propõem: o contato precoce com o trabalhador no ambiente do trabalho; intervenção nas acomodações do trabalho gerenciada por um especialista em ergonomia; facilitar a interação entre os membros da equipe multidisciplinar da saúde (médicos, fisioterapeutas e terapeutas ocupacionais); e os responsáveis pela empresa (diretores e supervisores). Além de adotar um programa de educação continuada sobre os aspectos ergonômicos e de segurança no local de trabalho. Citando estudos qualitativos, sugerem a necessidade de melhorar a comunicação entre as partes interessadas neste processo, sensibilizando e incentivando a participação dos colegas de trabalho; assim como delegar ao supervisor direto um importante papel para o retorno ao trabalho e eleger os profissionais da saúde como ponte de ligação entre o local de trabalho e o sistema de saúde.

Baseado no trabalho de Franche e colaboradores (2005), o Institute for Work \& Health do Canada (2007) recomenda às empresas adotarem os sete princípios para o sucesso no processo de retorno ao trabalho:1a existência de forte compromisso das pessoas no ambiente do trabalho com o retorno do trabalhador-doente; 2 - a necessidade de transformação no ambiente físico do local de trabalho para facilitar a readaptação do trabalhador com incapacidade temporária; 3- assegurar que o retor- 
no do trabalhador não sobrecarregue os colegas e cause dificuldade para o supervisor direto; 4- treinar os supervisores diretos do trabalhador sobre os processos envolvidos no retorno ao trabalho; 5- o empregador deve se comunicar o mais cedo possível com o trabalhador-doente e acompanhar o processo de retorno ao trabalho; 6- designar uma pessoa para coordenar o processo de retorno ao trabalho; e 7- empregadores e equipe multidisciplinar da saúde (médicos, enfermeiros, fisioterapeutas e terapeutas ocupacional) devem ficar em contato permanente e trocar informações sobre a recuperação do trabalhador-doente.

No Brasil, o processo de reabilitação profissional está regulamentado pela Lei 8.213/91, baseada na Convenção 159 da Organização Internacional do Trabalho e clamada pela $3^{\text {a }}$ Conferência Nacional de Saúde do Trabalhador realizada em 2005. A partir da Constituição de 1988, a reabilitação é uma atribuição do SUS; no entanto, as ações de saúde voltadas para a reabilitação profissional não foram integradas a este sistema nos últimos 20 anos, mantendo-se o INSS como o principal responsável pela reabilitação profissional para os trabalhadores celetistas. Contudo, as dificuldades crônicas de pessoal qualificado, o cunho assistencialista e previdenciário, o modelo convencional de reabilitação do trabalhador têm sido questionados quanto a sua eficácia, efetividade desse serviço e legitimação de seus objetivos. Não existe uma ação integrada com a participação da empresa, trabalhador e os diversos órgãos governamentais para mudar ou minimizar as condições de adoecimento. Com estas limitações expõem-se o trabalhador às mesmas situações que levaram ao seu afastamento. (TAHAKASHI, 2000; CUT, 2007)

$\mathrm{Na}$ atualidade há crescimento do debate sobre esta temática. A defesa da Previdência Social solidária, de gestão pública, democrática e universal deve ser rediscutida no âmbito da política nacional da saúde do trabalhador. O que se propõe é incorporar os diversos atores sociais na construção de um modelo gerencial que atenda às necessidades das partes interessadas na reabilitação profissional com igualdade de papéis e responsabilidades. O Estado como gestor deve tomar o seu papel de guardião das Leis e de regulador dos benefícios sociais e cidadania. (MAENO; TAKAHASHI; LIMA, 2009)

A legislação brasileira atual na área de saúde do trabalhador não faz distinção de direitos entre os empregados do setor privado, que trabalham regidos pela Consolidação das Leis Trabalhistas (CLT), e do 
servidor estatutário, regido pelo Regime Jurídico Único. Entretanto, o que se vê é um distanciamento das ações nos dois setores. Contudo, o setor público, que faz cumprir as normas de atenção à saúde e segurança do trabalhador nas empresas privadas, não consegue reproduzir os mesmos cuidados com os servidores estatutários. Este descompasso reflete a distância da administração pública em se apropriar da problemática para responder as demandas na área de saúde dos servidores, levando a um contingente crescente de afastados do trabalho por doença, em decorrência das condições de trabalho. (CARNEIRO, 2006)

Até recentemente os trabalhadores doentes do serviço público no Brasil eram acompanhados sem ter disponível uma estrutura organizada para cuidar da sua saúde. Ao longo dos anos foi desestimulada uma atenção especial com vista a promover melhoria das condições de saúde e de trabalho nas instituições. Este descaso levou a um número crescente de absenteísmo e aposentadoria precoce nessa população, com significativa repercussão socioeconômica. (DOMINGUES JÚNIOR, 2005)

\section{Considerações finais}

A revisão narrativa da literatura mostra, com base em diversos estudos, que o adoecimento do trabalhador, que interfere na sua capacidade laboral, pode ter repercussão no ambiente da família e interferir no processo de retorno ao trabalho. Entende-se que a família participa ativamente no gerenciamento do processo de adoecimento, através da mobilização de seus membros na contingência da convivência cotidiana. Este suporte é um fator importante na recuperação da incapacidade e pode ser considerado como um facilitador positivo para o retorno à condição laborativa o mais breve possível. (ROCHA, 2010)

Neste sentido, sugere-se que sejam revistas às práticas adotadas nos serviços de reabilitação, restrita ao indivíduo e ao ambiente de trabalho, entendendo-se que as fronteiras entre o trabalho e a família são flexíveis e permeáveis e indicando que o que acontece em um domínio influencia o outro domínio. Propõe-se, dentre as ações desenvolvidas para gerenciar a reabilitação profissional, incluir o gerenciamento dos processos que ocorrem na família neste contexto.

Por consequência, os profissionais envolvidos nesses processos devem procurar entender os horizontes de significados originados na 
interação familiar e incentivar, por exemplo, a mediação de conflitos entre os membros e ampliação do suporte social ao trabalhador-doente. A avaliação dessas famílias pode ser feita também se observando o contexto histórico e socioeconômico no qual esta está inserida durante o processo de desajuste, procurando-se respostas sobre a melhor forma de lidar com o problema. Os membros da família devem ser encorajados a desenvolver novos mecanismos e competências para compartilhar ações de suporte no sentido de fortalecer a família para superar obstáculos no gerenciamento da condição do trabalhador-doente e na possibilidade do retorno ao trabalho.

\section{Referências}

AGÊNCIA Brasil, [2008]. Disponível em: <http://www. agenciabrasil.gov.br/noticias /2008/05/13/materia.20080513. 929010578/view >. Acesso em: 10 jul. 2008.

ALEXANDERSON, K.; NORLUND, A. Chapter 1. Aim, background, key concepts, regulations, and current statistics. Scandinavian Journal of Public Health, v. 32, n. 63 Suppl. , p. 12-30, Oct. 2004.

ALLEBECK, P.; MASTEKAASA, A. Chapter 5. Risk factors for sick leave - general studies. Scandinavian Journal of Public Health, v. 32, n. 63 Suppl., p. 49-108, Oct. 2004.

BARIL, R.; BERTHELETTE, D.; MASSICOTTE, P. Early return to work of injured workers: multidimensional patterns of individual and organizational factors. Safety Science, v. 41, n. 4, p. 277-300, June 2003.

BARIL, R.; BERTHELETTE, D.; MASSICOTTE, P. Management of return-to-work programs for workers with musculoskeletal disorders: a qualitative study in three Canadian provinces. Social Science \& Medicine, v. 57, n. 11, p. 2101-2114, Dec. 2003.

BERNARDO, L. D. Os significados do trabalho e da reabilitação profissional para o trabalhador incapacitado para o exercício da profissão habitual. 2006. 72f. Dissertação (Mestrado em Saúde Pública) Faculdade de Medicina, Universidade Federal de Minas Gerais. Disponível em: < http://www. bibliotecadigital. ufmg. br /dspace/bitstream/1843/ ECJS-73BKA6/1/lilian_dias_bernardo. pdf>. Acesso em: 25 out. 2007.

BERTALANFFY, L. VON. General System Theory. 1 ed. New York, USA: George Braziller, 1969. 295 p. 
BLOCH, D. A. Foreword in Roland J S, Families, Illness, and Disability: an integrative treatment model. 1ed. New York, USA: Basic Books, 1994. 320p.

BODEN, L. I. et al. Social and economic impacts of workplace illness and Injury: current and future directions for research. American Journal of Industrial Medicine, v. 40, n. 4, p. 398-402, Oct. 2001. . Running on Empty: Families, Time, and Workplace Injuries. American Journal of Public Health, v. 95, n. 11, p. 1894-1897, Nov. 2005.

BOOT, C. R. L. et al. The role of illness perceptions in labor participation of the chronically ill. International Archives of Occupational and Environmental Health, v. 82, n. 1, p. 13-20, Jan. 2008.

BOUND, J. et al. Health, Economic Resources and the Work Decision of Older Men, 2003. Disponível em: <http://socserv. socsci. mcmaster. ca /cesg2003/stinepaper. pdf>. Acesso em: 10 jul. 2007.

BRANT, L. C.; MINAYO, C. G. A transformação do sofrimento em adoecimento: do nascimento da clínica à psicodinâmica do trabalho. Ciência \& Saúde Coletiva, v. 9, n. 1, p. 213-223, jan./mar. 2004. BURY, M. Chronic illness as biographical disruption. Sociology of health \& illness, v. 4, n. 2, p. 167-182, July 1982.

BURTON, J. et al. Evaluating the Social and Economic Consequences of Workplace Injury and Illness, 2002. Disponível em: < http://www.evaluationcanada.ca/distribution /20021030_rajan_rashmi.pdf>. Acesso em: 23 dez. 2009.

CARNEIRO, S. A. M. Saúde do trabalhador público: questão para a gestão de pessoas - a experiência na Prefeitura de São Paulo. Revista do Serviço Público, Brasília, v. 57, n. 1, p. 23-49, jan. /mar. 2006.

CERTEAU, M. The Pratice of Everyday life. 1 ed. United States of America: University of California Press, 1988, 229 p.

CHARMAZ, K. Loss of self: a fundamental form of suffering in the chronically ill. Sociology of Health and Illness, v. 5, n. 2, p. 168-195, July 1983.

CUT. Central Única do Trabalhador, BRASIL, 2007. Disponível em: $<$ http://www. cut. org. br/site/start. cut?infoid $=14883 \&$ sid $=22>$. Acesso em: 13 jul. 2008.

DEMBE, E. A. The Social Consequences of Occupational Injuries and Illnesses. American Journal of Industrial Medicine, v. 40, n. 5, p. 403-417, 2002. 
DEMBE, E. A. The Impact of Occupational Injuries and Illnesses on Families and Children. Center for Health Policy and Health Services Research. University of Massachusetts Medical School. 2003. Disponível em: <www. popcenter. umd. edu /events/ nichd/papers/dembe. pdf. > Acesso em: 21 jul. 2008.

DERSH, J. et al. The Management of Secondary Gain and Loss in Medicolegal Settings: Strengths and Weaknesses. Journal of Occupational Rehabilitation, v. 14, n. 4, p. 267- 729, Dec. 2004. DOMINGUES JÚNIOR, L. R. P. Trabalhar, Sim! Adoecer, Não! In: Conferência Nacional de Saúde do Trabalhador , III $^{\mathrm{a}}$ - Coletânea de Textos. 2005. Disponível em:<http://www. saude. ba. gov. br/ cesat/3aCNST/DOCAPOIO3CNST. pdf>. Acesso em: 04 nov. 2007.

ENGEL, G. L. The need for a New Medical Model: a challenge for Biomedicine. Science, v. 196, n. 4286, p. 129-136, Apr. 1977. Disponível em: < www. sciencemag. org >. Acesso em: 6 nov. 2008.

FERRARI, R.; KWAN, O.; FRIEL, J. Cognitive theory and illness behavior in disability syndromes. Medical Hypotheses, v. 57, n. 1, p. 68-75, July 2001.

FOREMAN, P.; MURPHY, G.; SWERISSEN, H. Barriers and facilitators to return to work: A literature review. Melbourne: Australian Institute for Primary Care, La Trobe University, 2006. Disponível em: <www. workcover. com/documents. aspx? fno=1353> Acesso em: 13 jul. 2008.

FRANCHE, R. L.; KRAUSE, N. Readiness for Return to Work Following Injury or Illness: Conceptualizing the Interpersonal Impact of Health Care, Workplace, and Insurance Factors. Journal of Occupational Rehabilitation, v. 12, n. 4, p. 233-256, Dec. 2002.

. Workplace-based return-to-work interventions: A systematic review of the quantitative literature. Journal of Occupational Rehabilitation, v. 15, n. 4, p. 525-542, Dec; 2005.

GALIZZI, M.; BODEN, L. I. The return to work of injured workers: evidence from matched unemployment insurance and workers compensation data. Labour Economics, v. 10, n. 3, p. 311-337, June 2003.

GELIJNS, A. C. Modern Methods of Clinical Investigation. 1. ed. Washington, DC, USA: National Academy Press, 1990, 244 p.

GATCHEL, R. J. et al. Psychosocial Factors That Can Influence the Self-Assessment of Function. Journal of Occupational Rehabilitation, v. 14, n. 3, p. 197-206, Sept. 2004.

GOMES, C. A. C. A Globalização da Defesa do Trabalho.

1. ed. Salvador, Bahia: UNIFACS, 2008, 206 p. 
HUSSERL, E. Phenomenology: its elementary forms. 14. ed. Chicago, USA; University of Chicago Press, 1946.

INSTITUTE FOR WORK \& HEALTH, Toronto Canada, 2007. Disponível em: <www. rubberassociation. ca/pdf_docs/SafetyGroups/2008/ RTW_7_principles. pdf >. Acesso em: 13 jul. 2008.

JANSEN, N. W. H. et al. Work-family conflict as a risk factor for sickness absence. Occupational \& Environmental Medicine, v. 63, n. 7, p. 488-494, July 2006.

KAISER, C. P. What Do We know About Employee Absence Behavior? An Interdisciplinary Interpretation. Journal of Socio-Economics, v. 27, n. 1, p. 79-96, Jan. 1998.

KELLY, R. The Illness Trajectory: understanding being ill as a sociological phenomenon, 2001. Disponível em: < http://ethnomethodologist. tripod. com /ethnomethodologyatwork /id3. html.> Acesso em: 24 maio 2009.

KLEINMAN, A. The Illness Narratives. 1. ed. United States of America: Basic Books, 1988. 284 p.

KWAN, O.; FRIEL, J. Clinical relevance of the sick role and secondary gain in the treatment of disability syndromes. Medical Hypotheses, v. 59, n. 2, p. 129-134, Aug. 2002.

LABRIOLA, M. Work environment factors associated with long-term sickness absence and return to work. Ph. D Thesis. Denmark: National Institute of Occupational Health, Institute of Public Health University of Copenhagen. 2006. 60p. Disponível em: $<$ www. arbejdsmiljoforskning. dk/upload/mla phd. pdf > . Acesso em: 13 jul. 2008.

LOISEL, P. Pshychosocial Semiotics: The Specific Paradigm of Work Rehabilitation. Cognitio-Estudos: Revista eletrônica de Filosofia, v. 4, n. 1, p. 20-24, Jun. 2007. Disponível em:< http:// www. pucsp. br/pos/filosofia/Pragmatismo/cognitio_estudos/ cognitio_estudos. htm>. Acesso em: 7 jan. 2010. . Intervention for return to work: What is really effective? (editorial). Scadinavian Journal of Work Environmental and Health, v. 31, n. 4, p. 245-247. 2005.

. et al. Management of occupational back pain: the Sherbrooke model. Results of a pilot and feasibility study. Occupational and Environmental Medicine. v. 51, p. 597-602, 1994. 
MAENO, M.; TAKAHASHI, M. A.; LIMA, M. A. G.

Reabilitação profissional como política de inclusão social.

Acta Fisiátrica, v. 16, n. 2, p. 53-58, Jun. 2009.

NIOSH (NATIONAL INSTITUTE FOR OCUPATIONAL SAFETY

AND HEALTH), 1996. Disponível em:< http://www. cdc. gov/

niosh/programs/workorg/>. Acesso em: 05 fev. 2010.

ORGANIZAÇÃO INTERNACIONAL DO TRABALHO. Convenção $\mathrm{n}^{\circ} 159$, da Organização Internacional do Trabalho - OIT, sobre Reabilitação Profissional e Emprego de Pessoas Deficientes. Disponível em: <http://www. ilo. org/skills /what/pubs/lang--en/ docName--WCMS_103529/index. htm. Acesso em: 17 jan. 2010.

PARSONS, T. Social structure and personality. 1. ed. New York, USA; The Free Press, 1964. 376 p.

ROCHA, P. R. F. O trabalhador-doente e sua família nos seus papéis como atores sociais no processo de retorno ao trabalho. 2010, 120f. Dissertação (Mestrado em Saúde, Ambiente e Trabalho) - Faculdade de Medicina, Universidade Federal da Bahia, 2010. Disponível em: < http://www. sat. ufba. br/site/db/dissertacoes/1462010141107. pdf>. Acesso em: 18 jan. 2012.

ROLLAND, J S. Families, Illness, and Disability: an integrative treatment model. 1. ed. New York, USA: Basic Books, 1994, 320 p.

SACHS, P. R.; ELLENBERG, D. B. The family system and adaptation to an injured worker. American Journal of Family Therapy, v. 22, n. 3, p. 263-272, July 1994.

SCHULTZ, I. Z.; STEWART, A. M. Disentangling the Disability Quagmire in Psychological Injury and Law. Psychological Injury and Law, v. 1, n. 2, p. 103-21, June 2008.

SIMIONATO, M. A. W.; OLIVEIRA. R. G. Funções e transformações da família ao longo da história, 2003. Disponível em:<www.abpp.com.br/ abppprnorte/pdf/a07Simionato03. pdf. Acesso em: 20 de maio de 2008.

SINGLY, F. Sociologia da Família Contemporânea. 1. ed. Rio de Janeiro, Brasil: Editora FGV, 2007. 208 p.

SLAVIN, R. E. Best evidence synthesis: an intelligent alternative to metaanalysis. Journal of Clinical Epidemiology, v. 48, n. 1, p. 9-18 1995.

STRUNIN. L.; BODEN, L. I. Family consequences of chronic back pain. Social Science \& Medicine, v. 58, n. 7, p. 1385-1393, 2004.

TAKAHASHI, M. A. C. Avaliação em Reabilitação Profissional. A experiência de adoecer por LER e o resgate da autonomia: uma 
trajetória singular. 2000, 111f. Dissertação (Mestrado em Ciências Medicas) - Faculdade de Ciências Médicas, Universidade Estadual de Campinas, 2000. Disponível em:<http://libdigi.unicamp.br / document/?code $=$ vtls000197873 $>$. Acesso em: 23 jan. 2010.

VAHTERA, J.; PENTTI, J.; KIVIMA, M. Health Sickness absence as a predictor of mortality among maleand female employees. Journal of Epidemiology and Community Health, v. 58, n. 4, p. 321-326, Apr. 2004.

VINGÅRD, N. E. et al. Long-term sick-listing among women in the public sector and its associations with age, social situation, lifestyle, and work factors: A three-year follow-up study. Scandinavian Journal of Public Health, v. 33, n. 5, p. 370-375, Oct. 2005.

WADDELL, G.; BURTON, K. Concepts of rehabilitation for the management of common health problems, 2004. Disponível em: <http:// www. workingforhealth.gov.uk/documents/concepts-of-rehabilitation.pdf. Acesso em: 01 nov. 2009.

WADDELL, G.; BURTON, K. Is Work Good for your Health and Wellbeing?, 2006. Disponível em: <http://books. google. com/ books?hl=ptBR\&lr $=\& i d=b E Z l E m z n J c c C \& o i=$ fnd \&pg $=$ PR $5 \& d q=I s+$ Work + Good + for + your ++ Health + and ++ Wellbeing\%3F $+2006 \&$ ots $=8 \mathrm{JCI} 8432 \mathrm{M}$ $z \& s i g=1$ P86etqUMQMuu7rABpio0-bW0u42006>. Acesso em: 13 jul. 2008.

WHO (WORLD HEALTH ORGANIZATION). The WHO Family of International Classifications. Disponível em:

< http://www. who. int/classifications/en>. Acesso em: 24 mar 2009.

WALSH, F. The Concept of Family Resilience: Crisis and Challenge. Family Process, v. 35, n. 3, p. 261-81, Sept. 1996.

YOUNG, A. E. et al. A Developmental Conceptualization of Return to Work. Journal of Occupational Rehabilitation, v. 15, n. 4, p. 557-568, Dec. 2005. 